MASTER

QIKMIX: A Quick-Turnaround Computer Program for Computing Opacities of Mixtures 
LA.7724-M

Mariual

Special Distribution

Issued: May 1979

\title{
QIKMIX: A Quick-Turnaround Computer Program for Computing Opacities of Mixtures
}

\author{
J. Abdallah, Jr. \\ W. F. Huebner
}

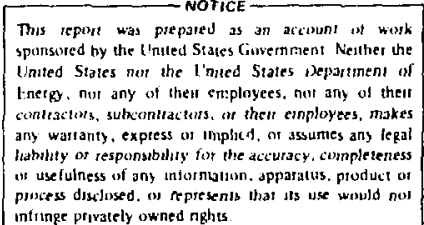

inf Inge privstely owned nghts.

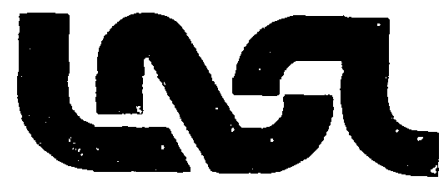




\title{
QIKMIX: A QUICK-TURNAROUND COMPUTER PROGRAM FOR COMPUTING OPACITIES OF MIXTURES
}

by

\author{
J. Abdallah, Jr., and W. F. Huebner
}

\begin{abstract}
QIKMIX is a quick-turnaround computer code developed to compute the radiative Rosseland mean opacity of specified mixtures at specified temperature and density points. The QIKLIB data base, which QIKMIX uses, has been derived from the OPLIB library. For most mixtures, QIKMIX can compute cpacities over a temperature range of 50 to $25000 \mathrm{eV}$ in less than 1 min of CDC 7600 computer time. The purpose of this report is to discuss the QIKLIB data base and the operation of the QIKMIX code.
\end{abstract}

\section{INTRODUCTION}

QIKMIX was developed at the Los Alamos Scientific Laboratory (LASL) to provide a method of obtaining approximate values of the radiative Rosseland mean opacity $\left(\kappa_{R}\right)$ for mixtures of arbitrary composition without using the full OPLIB treatment. ${ }^{\prime}$ Thus the user can experiment with different compositions to get a rough estimate of their effects on the opacity. Users should be aware that the results of QIKMIX are intended to be estimates (within $\pm 20 \%$ of OPLIB results); for definitive results, OPLIB snould be used. However, QIKMIX will often give results that are within $1 \%$ of OPLIB results.

The method for computing the Rosseland mean opacity of a mixture of ions involves combining the reduced group mean extinction coefficients at each value of $u=h \nu / \mathrm{kT}^{*}$ for each component (in proportion to its number fraction) at each temperature (kT) and degeneracy parameter $(\eta)$ point on a fixed predetermined $(u, k T, \eta)$ grid. The resulting sets of extinction coefficients are integrated as a function of $u$ to obtain $\kappa_{R}$. This opacity table then may be interpolated to obtain $\kappa_{R}$ at the desired temperature and density points.

*Here, $h v$ is the photon energy. 
Until now, these computations have used the massive OPLIB data files described in Rei. 1. Note that each atomic component on OPLIB exists as a separate file. Although the use of OPLIB gives the best results available, the size and number of these files wigke data transfer siow and cumbersome even for simple mixtures.

QIKLIB, the data base used by QIKMIX, contains a subset of the OPLIB data plus averaged OPLIB extinction coefficients. QIKLIB is structured in a corvenie is form for performing the mixture calculation.

Section II gives a detailed description of the data base, Sec. $T^{\prime}$ scribes the input required by QIKMIX, and Sec. IV describes the output generated by or aIX. 


\section{DATA BASE DESCRIPTION}

QIKLIB consists of four files (QIK1, QIK2, QIK3, and QIK4), each containing data for different temperature regions. Table I shows the temperature points in each file. Note that all extinction coefficients are triple packed, and that more are necessary in the lower temperature regions to yield setisfactory results.

Each QIKn file consists of a file label (see Table I) followed by data records, one for each ( $k T$, $\eta, Z$ ) point, and then by an end-of-file mark (see Fig. 1). Each data record contains descriptive information and extinction coefficients. The detailed data record format is shown in Table II.

- Here $\mathrm{Z}$ is the atomic number of the mixture component.

TABLE I

QIKLIB FILE SUMMARY

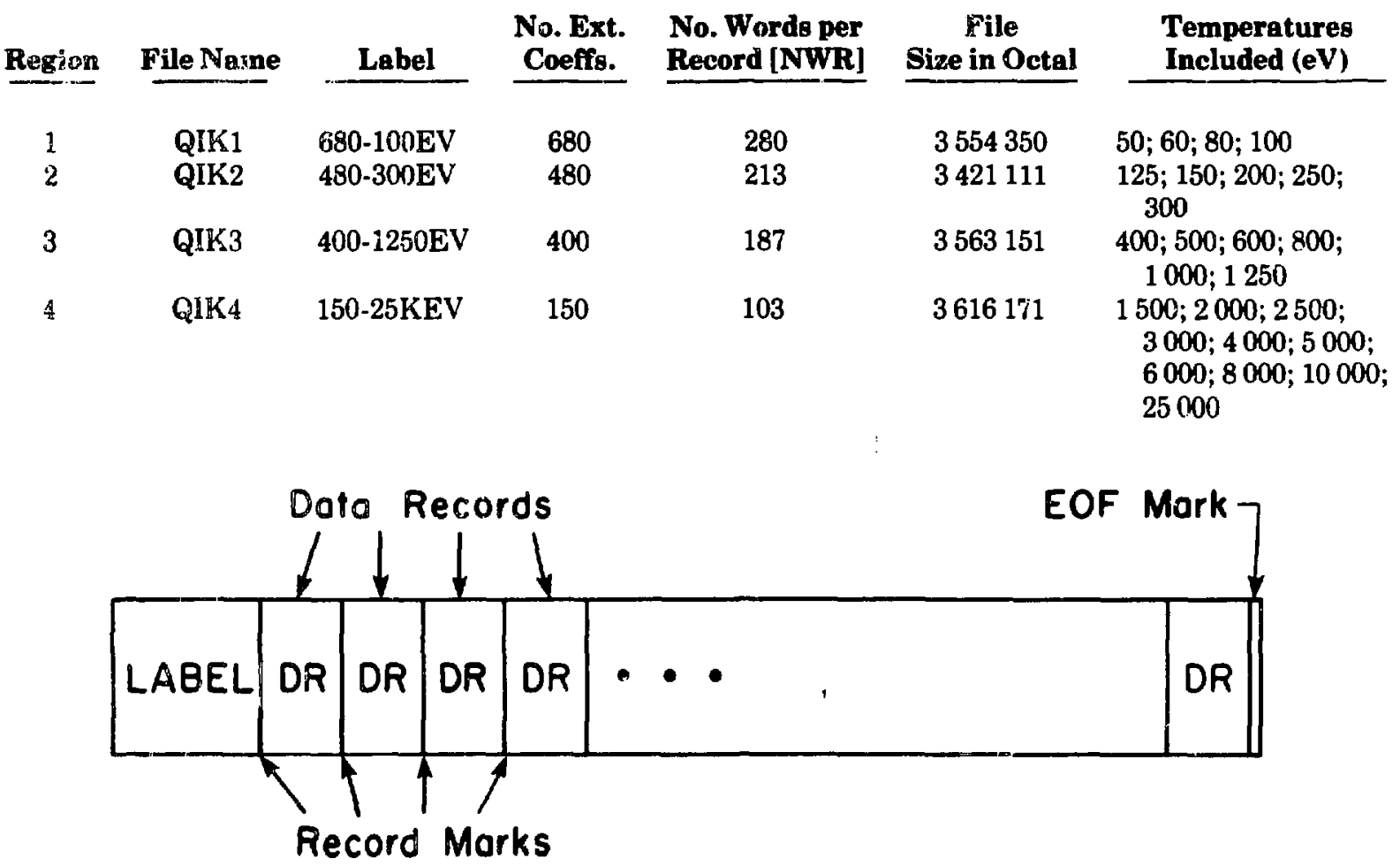

Fig. 1.

QIKn file structure. 


\section{QIKLIB DATA RECORD FORMAT ${ }^{a}$ (PURE ELEMENTS ONLY)}

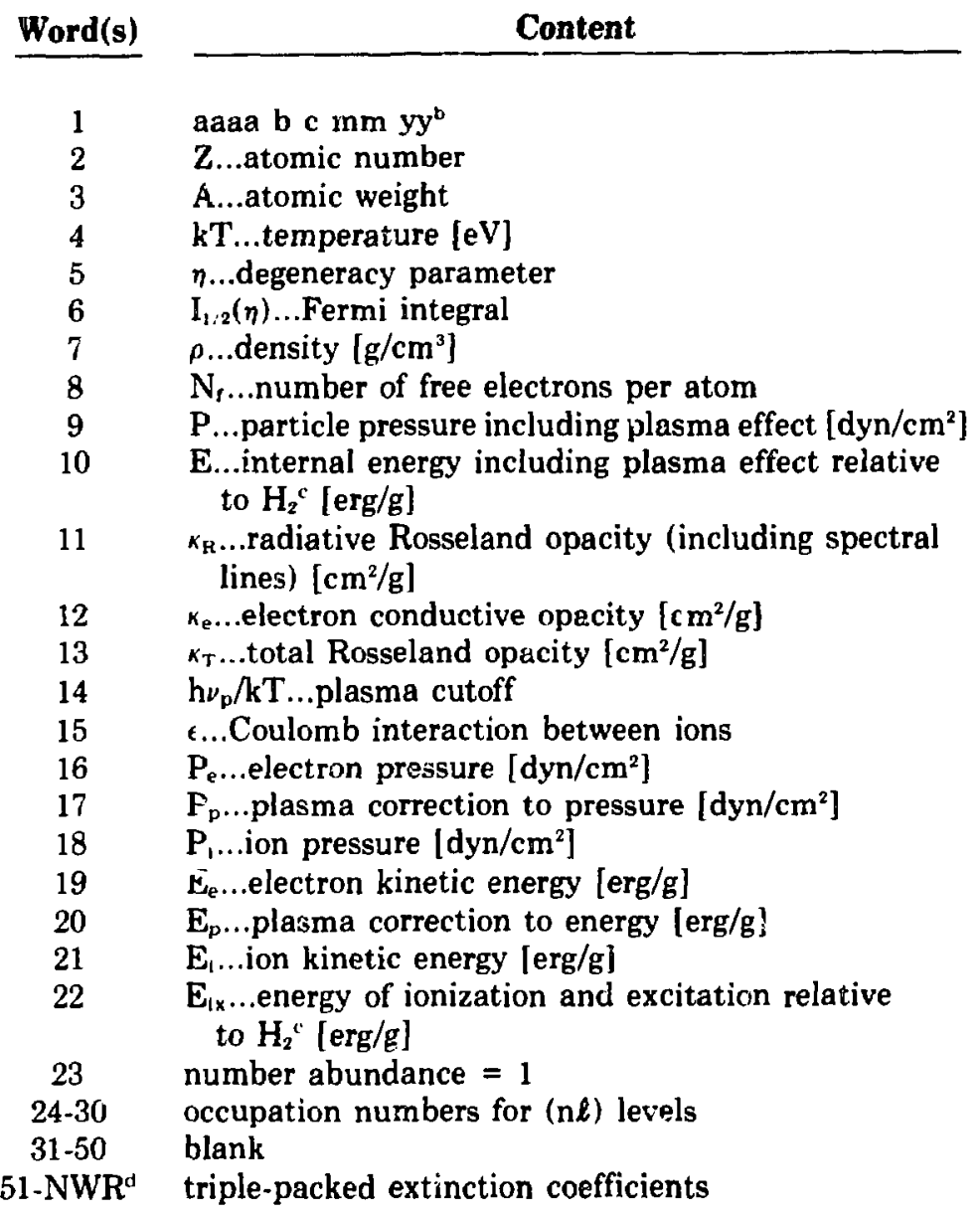

See Ref. 1 for detailed lescriptions of the parameters.

Daaa...number of OPLIB record from which data was extracted

$b=1$ or 2 ...mean ion model

$\mathrm{b}=3$...explicit ion model

$c=1$...electron conduction by Hubbard-Lampe model

$c=2$...electron conduction by Mestel model

mm...month of code used to calculate OPLIB opacity

yy...year of code used to calculate OPLIB opacity

To obtain the energy relative to the isolated neutral atom, suibstract the dissociation anergy of $\mathrm{H}_{3}, 2.15 \times 10^{\mathrm{kt}} \mathrm{erg} / \mathrm{g}$.

NWR is defined in Table I. 
Note that some parameters such as pressure and energy are included on the data base but not used by QIKMIX. These parameters may be used in future applications as the need arises. A list of the 24 currently available elements is shown in Table III. Space has been reserved for additional elements as they become available. Table IV shows the $36 \eta$ values used to generate the QIKLIB grid. If no data exist for a given $(\mathrm{kT}, \eta, Z)$ point, the entire record is zeroed out except for words 2,4 , and 5 . The records are sorted in $k T$, then $\eta$, and then $Z$, all in monotonically increasing order. Therefore, $(50,-25,1)$ occurs first, $(50,-25,2)$ occurs next, etc. The multi-element feature of QIKLIB facilitates processing for the QIKMIX code, because records corresponding to elements not in the desired mixture are skipped.

All sets of extinction coefficients in QIKLIB are group averages of those appearing on OPLIB between $u=0$ and $u=20$. Because the OPLIB spacing is 0.01 , the set of 2000 OPLIB cnefficients is reduced to the number of QIKLIB coefficients shown in Table I for each of the temperature regions. QIKLIB averaged coefficients are generated in each region starting at $u_{A}$ and ending at $u_{B}$ in steps of $\Delta u$. Thus more coefficients may be retained in frequency ranges that contribute more to the opacity in various temperature ranges. Table $V$ summarizes the $u$ values for which extinction coefficients exist in each of the QIKLIB temperature regions.

TABLE III

\section{CURRENTLY AVAILABLE MIXTURE COMPONENTS}

\begin{tabular}{|c|c|c|}
\hline Component & $\mathbf{Z}$ & Component \\
\hline Hydrogen & 1 & Silicon \\
\hline Helium & 2 & Phosphorus \\
\hline Lithium & 3 & Sulfur \\
\hline Beryllium & 4 & Chlorine \\
\hline Boron & 5 & Argon \\
\hline Carbon & 6 & Potassium \\
\hline Nitrogen & 7 & Calcium \\
\hline Oxygen & 8 & Titanium \\
\hline Neon & 10 & Chromium \\
\hline Sodium & 11 & Manganese \\
\hline Magnesium & 12 & Iron \\
\hline Aluminum & 13 & Nickel \\
\hline
\end{tabular}

TABLE IV

\section{VALUES OF $\eta$ FOR QIKLIB GRID GENERATION}

$\begin{array}{rrrr}-25 & -16 & -7 & 5 \\ -24 & -15 & -6 & 8 \\ -23 & -14 & -5 & 12 \\ -22 & -13 & -4 & 20 \\ -21 & -12 & -3 & 30 \\ -20 & -11 & -2 & 50 \\ -19 & -10 & -1 & 80 \\ -18 & -9 & 1 & 120 \\ -17 & -8 & 3 & 200\end{array}$




\section{TABLEV}

VALUES OF U ASSOCIATED WITH STORED EXTINCTION COEFFICIENTS

\begin{tabular}{|c|c|c|c|c|}
\hline $\begin{array}{c}\text { Teniperature } \\
\text { Region }\end{array}$ & $\mathbf{u}_{\mathbf{A}}$ & $\mathbf{u}_{\mathrm{B}}$ & Au & Number \\
\hline \multirow{6}{*}{1} & 0.5 & 1.0 & 0.5 & 2 \\
\hline & 1.02 & 2.0 & 0.02 & 50 \\
\hline & 2.01 & 6.0 & 0.01 & 400 \\
\hline & 6.02 & 10.0 & 0.02 & 200 \\
\hline & 10.1 & 12.0 & 0.1 & 20 \\
\hline & 13.0 & 20.0 & 1.0 & $\frac{8}{680 \text { Total }}$ \\
\hline \multirow[t]{4}{*}{2} & 0.5 & 1.0 & 0.5 & 2 \\
\hline & 1.02 & 10.0 & 0.02 & 4.50 \\
\hline & 10.1 & 12.0 & 0.1 & 20 \\
\hline & 13.0 & 20.0 & 1.0 & $\frac{8}{480 \text { Total }}$ \\
\hline \multirow[t]{4}{*}{3} & 0.5 & 1.0 & 0.5 & 2 \\
\hline & 1.02 & 8.0 & 0.02 & 350 \\
\hline & 8.1 & 12.0 & 0.1 & 40 \\
\hline & 13.0 & 20.0 & 1.0 & $\frac{8}{400 \text { Total }}$ \\
\hline \multirow[t]{5}{*}{4} & 0.5 & 1.0 & 0.5 & 2 \\
\hline & 1.1 & 3.0 & 0.1 & 20 \\
\hline & 3.05 & 8.0 & 0.05 & 100 \\
\hline & 8.2 & 12.0 & 0.2 & 20 \\
\hline & 13.0 & 20.0 & 1.0 & $\frac{8}{150 \text { Totel }}$ \\
\hline
\end{tabular}




\section{QIKMIX INPUT}

Core storage requirements for program: 63064 words (octal) $=26124$ words (decimal) Disk storage requirements for data: 16577023 words (octal) = 3866131 words (decimal) Input to QIKMIX consists of the QIKLIB data base described in the previous section and a control card file QKCTRI. QIK1 and QIK2 exiet as a library (LIX) file QIKLBO on LASL HYDRA photostore under access code T4QIK. Similarly, QIK3 and QIK4 exist as QIKLB1 under the same access code. QIKMIX will automatically retrieve these files from photostore and perform the required LIX operation.

QKCTRL contains control information used by QIKMIX (see Table VI for the QKCTRL format). This control file was introduced to facilitate batch processing and to help the user avoid the repetition of entering the same data on consecutive runs of QIKMIX (which could occur if QIKMIX is used interactively). The data entered into QKCTRL include the composition of the mixture, the density points, and the temperature points for which opacities are to be generated. The mixture composition may be entered as molecular formulas and as individual elements. The number of unique elements in the mixture must not exceed 1.5 because of dimension statement limitations in the program. The composition information is used to generate internal tables, which include temperatures, densities, and opacities at the fixed (kT, $\eta$ ) grid. Opacities are generated at the requested temperatures and densities by interpolating on this set of internal tables. These tables are output by QIKMIX (as the binary file QKTBLS) and also may be used as input (see Sec. IV). IRI and IR2 (see Table VI) may be set to nonzero values to obtain a quicker mixture calculation, but the user should be aware that the internal tables generated will not include the full range of temperatures.

Figure 2 shows a sample control card nile for a mixture of 1 part aluminum to 100 parts ${ }^{\circ} \mathrm{Li}^{2.6} \mathrm{H}$, where ${ }^{2.0} \mathrm{H}$ represents a 1-to-1 mixture of deuterium and tritium. Note that two atomic weight override cards are necessary. Also note that QIKMIX will renormalize the number or weight fractions that were specified in the input.

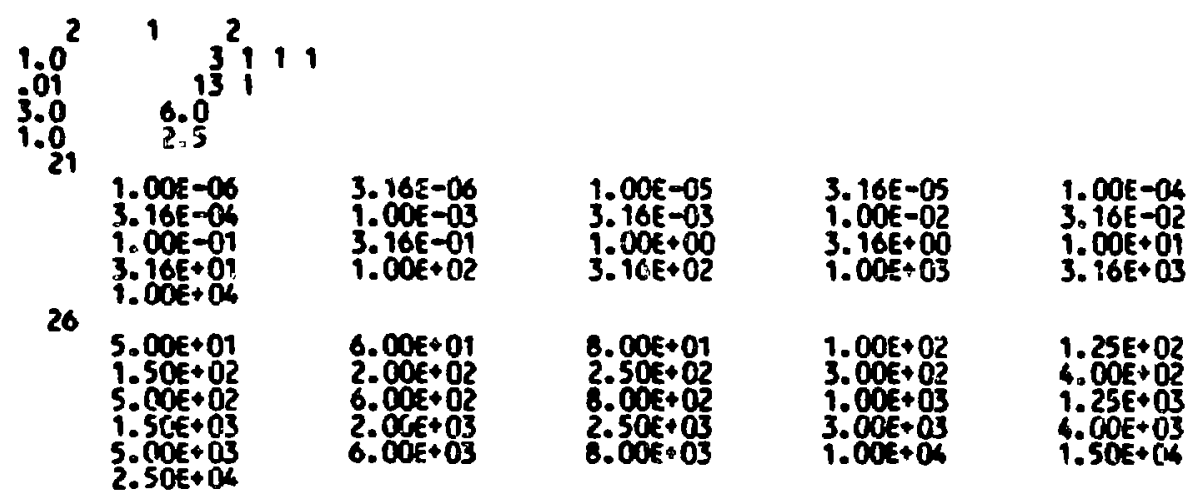

Fig. 2.

Sample QKCTRL file for 1 part aluminum to 100 parts ${ }^{\theta} \mathrm{Li}^{2 . s} \mathrm{H}$. 


\section{TABLE VI}

\section{QKCTRL FORMAT}

\begin{tabular}{|c|c|c|c|}
\hline Card & Format & Parameter & Description \\
\hline \multirow[b]{4}{*}{ - } & $(1 \mathrm{X}, \mathrm{I} 4,4 \mathrm{I} 5)$ & NMOL & $\begin{array}{l}\text { |NMOL equals the number } \\
\text { of molecules and individual atoms input. } \\
\text { If NMOL }<0 \text {, previously generated } \\
\text { internal tabies are read in from } \\
\text { file QKTBLS (see Sec. IV) and } \\
\text { interpolation is performed. }\end{array}$ \\
\hline & & NORWTF & $\begin{array}{l}\text { If NORWTF }=0 \text {, input is in weight } \\
\text { fractions. If NORWTF }=1 \text {, input is in } \\
\text { number fractions. }\end{array}$ \\
\hline & & NI & $\begin{array}{l}\text { Number of atomic weight overrides. } \\
\text { Atomic weight overrides are included } \\
\text { to allow the user to input atomic } \\
\text { weights other than those on QIKLIB. } \\
\text { Thus, different isotopes can be } \\
\text { accounted for. }\end{array}$ \\
\hline & & IR1, IR2 & $\begin{array}{l}\text { If IR1 and IR2 are other than } 0 \text {, } \\
\text { QIKMIX is forced to use only temperature } \\
\text { regions IR1 to IR2 (IR1 } \leq \text { IR2) in } \\
\text { the mixture calculation. If both } \\
\text { are } 0 \mathrm{o}_{+} \text {. nitted, all four regions } \\
\text { are used. }\end{array}$ \\
\hline $\begin{array}{l}\text { Next NMOL } \\
\text { cards }\end{array}$ & $\begin{array}{l}(1 \mathrm{X}, \mathrm{E} 11.0 \\
16 \mathrm{~F} 2.0)\end{array}$ & ALFABET & $\begin{array}{l}\text { Number or weight fraction depending } \\
\text { on value of NORWTF for the molecule. }\end{array}$ \\
\hline & & $\begin{array}{l}(Z, S) \\
\text { repeating } \\
\text { group }\end{array}$ & $\begin{array}{l}\text { Atomic number of molecular } \\
\text { constituent and its associated } \\
\text { subscript (stoichiometric coefícient). A } \\
\text { maximum of eight elements may appear } \\
\text { in each molecular formula. }\end{array}$ \\
\hline $\begin{array}{l}\text { Next NI } \\
\text { cards } \\
\text { (if any) }\end{array}$ & $\begin{array}{l}(1 \mathrm{X}, \mathrm{F} 9.5 \\
\text { F10.5) }\end{array}$ & ZI, AI & $\begin{array}{l}\text { Atomic weight override cards. } \\
\text { ZI is the atomic number of } \\
\text { the element whose atomic weight is to } \\
\text { be overriden, and AI is the atomic weight } \\
\text { override (weight of isotope). }\end{array}$ \\
\hline Next card & $(1 \mathrm{X}, \mathrm{I} 4)$ & NRU & $\begin{array}{l}\text { Number of densities requested. The } \\
\text { maximum value of NRU is } 21 \text {. }\end{array}$ \\
\hline Next cards & (5E15.8) & RHOTBL & $\begin{array}{l}\text { Densities requested }\left(\mathrm{g} / \mathrm{cm}^{3}\right) ; \text { as } \\
\text { many cards as required by NRU. }\end{array}$ \\
\hline Next card & $(1 \mathrm{X}, 14)$ & NTU & $\begin{array}{l}\text { Number of temperatures requested. } \\
\text { The maximum value of NTU is } 26 \text {. }\end{array}$ \\
\hline Next cards & (5E15.8) & TEVR & $\begin{array}{l}\text { Temperatures requested }(\mathrm{eV}) \text {; as many } \\
\text { cards as required by NTU. }\end{array}$ \\
\hline
\end{tabular}




\section{QIKMIX OUTPUT}

Output from QIKMIX consists of a file of internal tables of mixture opacities at the fixed (kT, $\eta$ ) grid points (QKTBLS) and an output file listing the mixture opacities at the desired temperature-density grid points (QKLIST).

QKTBLS can be used as input to QIKMIX when the user wants to generate more points for a previcusly processed mixture. To initiate this, set NMOL negacive (see Table VI), set the new temperature-density grid, and execute QIKMIX. The internal tables will be read from QKTBLS by QIKMIX to avoid repeating the time-consuming mixture calculation.

Figure 3 shows the output file (QKLIST) generated by the execution of QIKMIX using QKCTRL as shown in Fig. 2. It includes a listing of the control cards, a summary of the contents of QIKLIB, a summary of the molecular and atomic fractions input, and a listing of $\kappa_{R}$ at the requested grid points. Note that blanks appear at grid points for which no $\kappa_{\mathrm{R}}$ could be computed.

\section{REFERENCE}

1. W. F. Huebner, A. L. Merts, N. H. Magee, Jr., and M. F. Argo, "Astrophysical Opacity Library," Los Alamos Scientific Laboratory report LA-67E0-M (August 1977). 
₹ aIKHIX contaOL CAROS

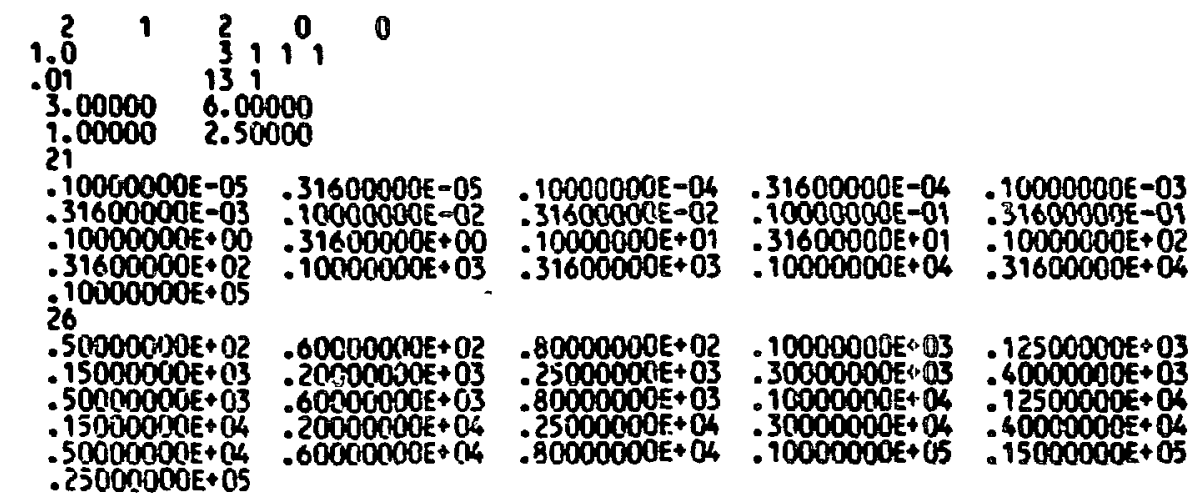

OPACITY FILE 680-100EV CONTALAS 24 ELEMENTS

\begin{tabular}{|c|c|}
\hline $\begin{array}{r}\text { ATomic } 10 \\
1.00000 \\
2.00000 \\
3.00000 \\
4.00000 \\
5.00000 \\
6.00000 \\
7.00000 \\
8.00000 \\
10.00000 \\
11.00000 \\
12.00000 \\
13.00000 \\
14.000000 \\
15.00000 \\
16.00000 \\
17.00000 \\
18.00000 \\
19.00000 \\
20.00000 \\
22.00000 \\
24.00000 \\
25.00000 \\
26.00000 \\
28.00000\end{array}$ & $\begin{array}{r}\text { ATOHIC NT } \\
1.00800 \\
4.00300 \\
6.94000 \\
9.01300 \\
10.82000 \\
12.01100 \\
14.00000 \\
16.00000 \\
20.16300 \\
22.99100 \\
24.32000 \\
26.99000 \\
28.09000 \\
30.97500 \\
32.06000 \\
35.45700 \\
39.94400 \\
39.10000 \\
40.08000 \\
47.90000 \\
52.01000 \\
54.94000 \\
55.95000 \\
58.910000\end{array}$ \\
\hline
\end{tabular}

Fig. 3.

QKLIST file listing generated by executing QIKMIX with the QKCTRL control cards shown in Fig. 2. 
IMPUT DATA MOLECULAR FRACTIONS

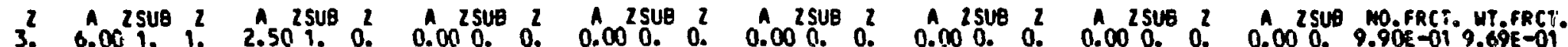

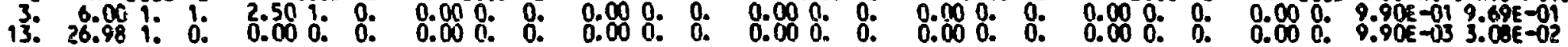

ATOMIC FRACTIONS

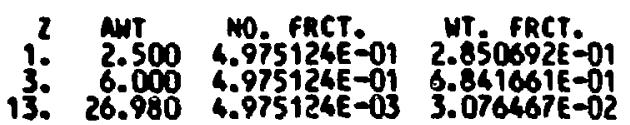

SUMA $1.00000000 E+00$ SUMNR $=2.05672637 E+C O$ SLMANE $=4.36308458 E+C O$

DEMSITY GRIO (G/CC)

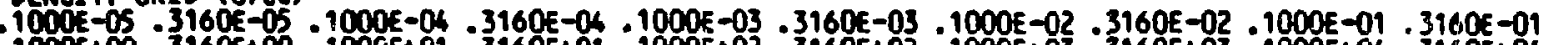
$.1000 E+00: 3160 E+00: 1000 E+01.3160 E+01: 1000 E+02: 3160 E+02: 1000 E+03: 3160 E+03: 1000 E+04: 3160 E+04$ $1000 E+05$

T(EV) ROSSELAND mEAN OPACITIES OF mIXTURE AT REQUESTEO GRID

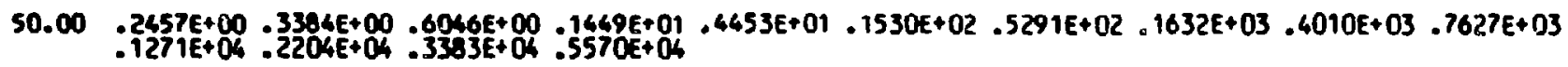
$60.00 \quad .2138 E+00.2590 E+00.3786 E+00.7207 E+00.1850 E+01.5882 E+01.1982 E+02-6317 E+02.1582 E+03-3237 E+03$
$.5584 E+03.949 E+03.1651 E+04.2660 E+04$

$80.00 .1965 E+00 \quad .2098 E+00.2456 E+00.3361 E+00.5974 E+00.1390 E+01.3052 E+01.1114 E+02.2978 E+02.6881 E+02$ $.1363 \mathrm{E}+03.2702 E+03.5067 \mathrm{E}+03.8555 \mathrm{E}+03$ $100.00 \cdot .1914 E+00 \cdot 1962 E+00.2093 E+00-2436 E+00.3294 E+00.5564 E+00.1176 E+01 \quad .2872 E+01.7407 E+01.1890 E+02$

$125.00 \cdot 1913 E+00 \cdot 1932 E+00.1984 E+00.2118 E+00 \cdot 2464 E+00.3247 E+00.5110 E+00.9781 E+00.2197 E+01.5384 E+01$ $.1325 E+02.3041 E+02.7465 E+02.1601 E+03.3008 E+03$

Fig. 3. (cont) 


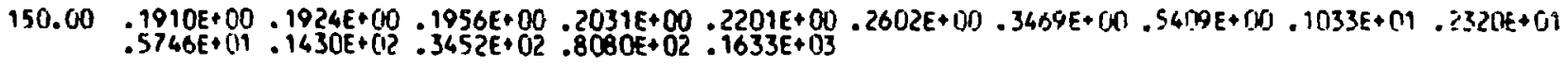

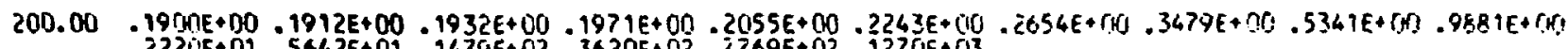
$.2220 E+01: .5642 E+01: 1479 E+02: 3620 E+02 \div .1769 E+02: 1270 E+03$

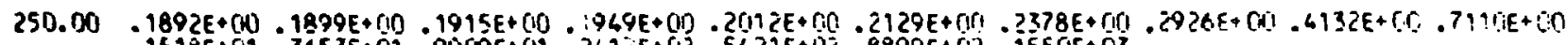

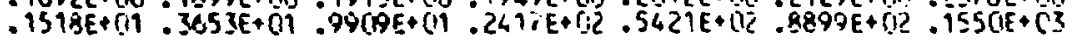

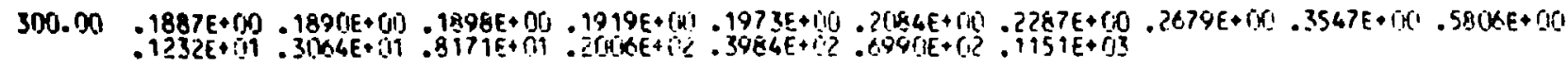

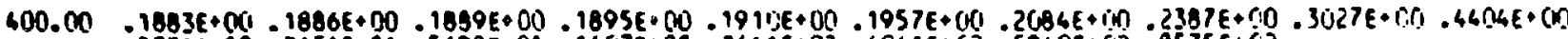

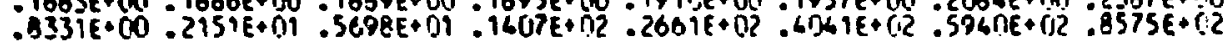

$500.00-1876 E+00-1877 E+00.1877 E+00.188 C E+00.1887 E+00.1900 E+C O N .1959 E+00.2098 E+00.2670 E+C 00.3386 E+C K O$

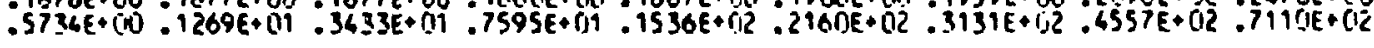

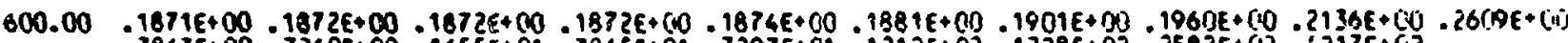
$.3863 E+000.7260 E+00: 1655 E+01: 3865 E+01: .7293 E+01.1212 E+02: 1728 E+02 . .2582 E+132: .4217 E+E, 2$

$890.00-1862 E+00-1862 E+00.1862 E+00.1862 E+00.1863 E+00.1854 E+00-1870 E+00.1886 E+100.1931 E+100.2064 E+150$ $.2426 E+00: 3340 E+00.5496 E+00: .1063 E+01: 2038 E+101.3521 E+01.0053 E+01: 1014 E+(12: .1752 E+02.2940 E+02$

$1000.00-1852 E+00.1852 E+00 \cdot 1852 E+00.1852 E+00.1853 E+0 D .1853 E+00.1855 E+00.18 B 2 E+00.18805+00.1932 E+00$

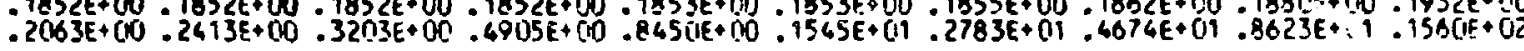

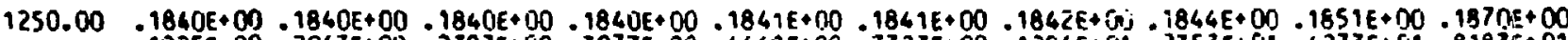

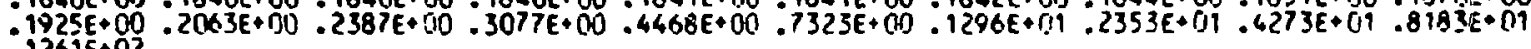
$1261 E+n \underline{Z}$

Fig. 3. (cont) 


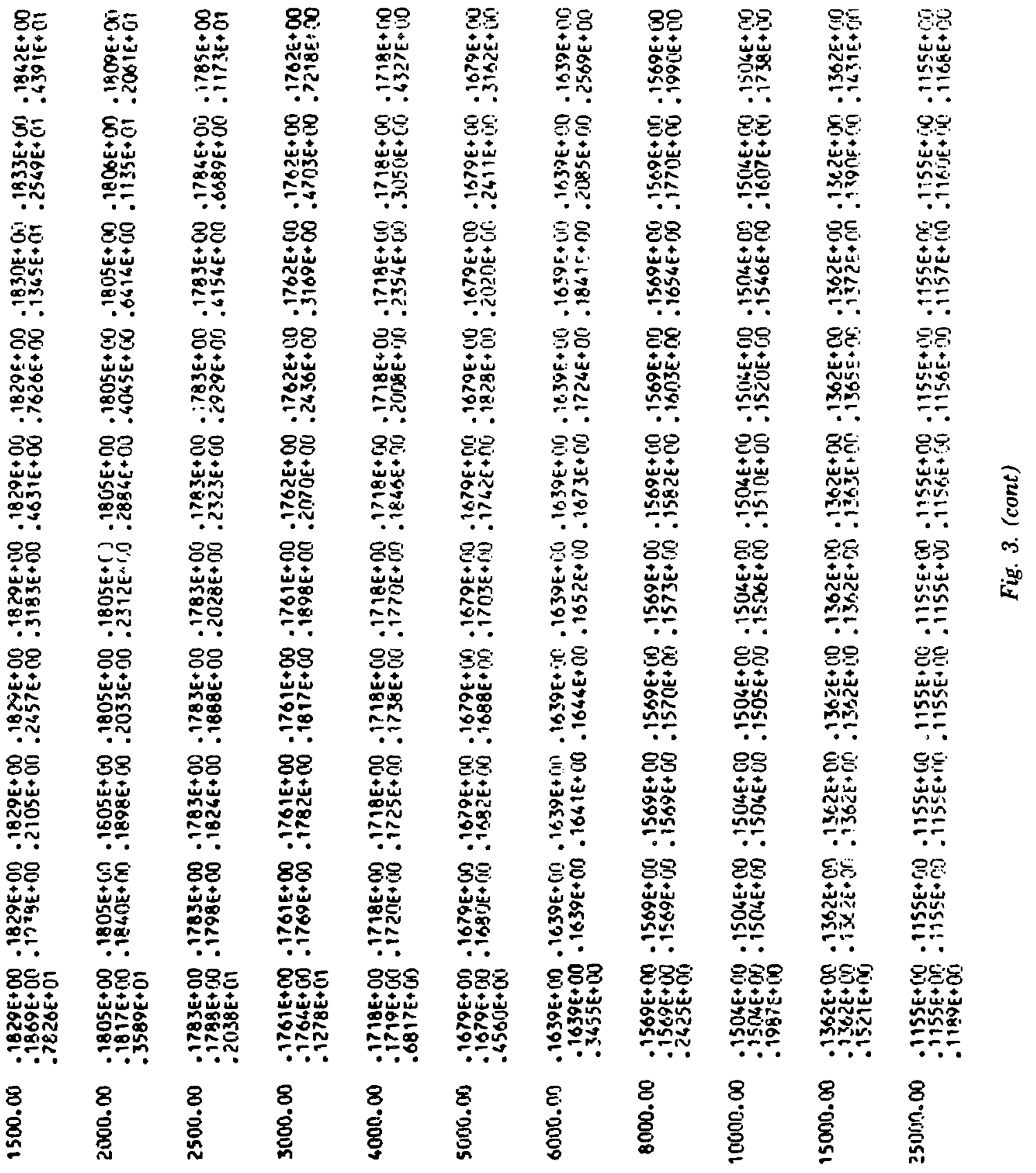

